\title{
Coproductions: Material, light, architecture
}

\author{
BEAMS Light Festival 2012 \\ Report by Sandra Karina Löschke
}

Coproductions is an interdisciplinary design studio offered as a collaborative venture between the UTS Masters in Architecture and Masters in Lighting Design. Collaborating in teams of three to four, students explored the interplay between material, light and space to create illuminated public sculptures for the 2012 BEAMS light festival. The challenge was to create works that were innovative in their combined use of lighting and material technologies but also functional and engaging, making a contribution to the activation of the neighbourhood.

BEAMS was an initiative of the Chippendale Creative Precinct, a group of art galleries, designers, video producers and digital media companies who joined forces to attract life to the traditional working class area and raise its profile. The event was supported by Frasers Property Australia whose Central Park development on the adjacent Carlton Brewery site is expected to bring thousands of new residents to the area in coming years, and the City of Sydney whose ongoing initiatives to activate Sydney's laneways successfully injected new energy into previously isolated urban areas.

Over a period of six weeks, postgraduate architecture and lighting design students toiled over large sculptural installations and urban furniture pieces. The interdisciplinary team structure was intended to overcome traditional models of collaboration which regard lighting as a secondary consideration that follows the completion of the architectural design phase as an afterthought. In contrast, mixed teams of coproducers explored the full potential of material and spatial possibilities, broadening the disciplinary horizons of all involved.

Experiments were set up, documented and evaluated; partial proto-types for structures were tested, adapted and refined; materials were sourced, sponsorships negotiated and elements prefabricated; potential sites were surveyed, lighting conditions analysed and fixtures negotiated with building owners. On the afternoon of the festival day, eight teams formed by eighteen architecture students and six lighting design students finally made their way to the site to set up their pieces within only a few hours before darkness set in and the spectacle began. Between $5 \mathrm{pm}$ and 10pm, Balfour Street and the surrounding streets leading off Abercrombie Street were pedestrianised and illuminated for the inaugural BEAMS festival. An estimated 5000 visitors descended upon the small neighbourhood area, socialising, celebrating and curiously exploring the illuminated objects on show.

Ideas about audience engagement and participation were addressed by the student teams in a number of imaginative ways. Sociolantern, an "infrastructural object” fabricated from corrugated cardboard ribs, layered with reflective foil and integrated lighting, invited public engagement by returning a sense of spectacle to the urban landscape. Combining digital tectonics with seating and illumination, the project explored the interstice between art and utility. The modular bench was anticipated to behave like a lantern, inviting passers-by to pause, interact, and reclaim the nocturnal spaces of the city. The team argued that the design of urban furniture was largely uninviting in nature, conceived to prevent unnecessary 
activities and lingering. This was something that they sought to oppose with SOCIOlantern in rethinking the functions of lighting and seating but also reconsidering the aesthetic potential of urban "infrastructural objects" and their capacity to promote meaningful activities.
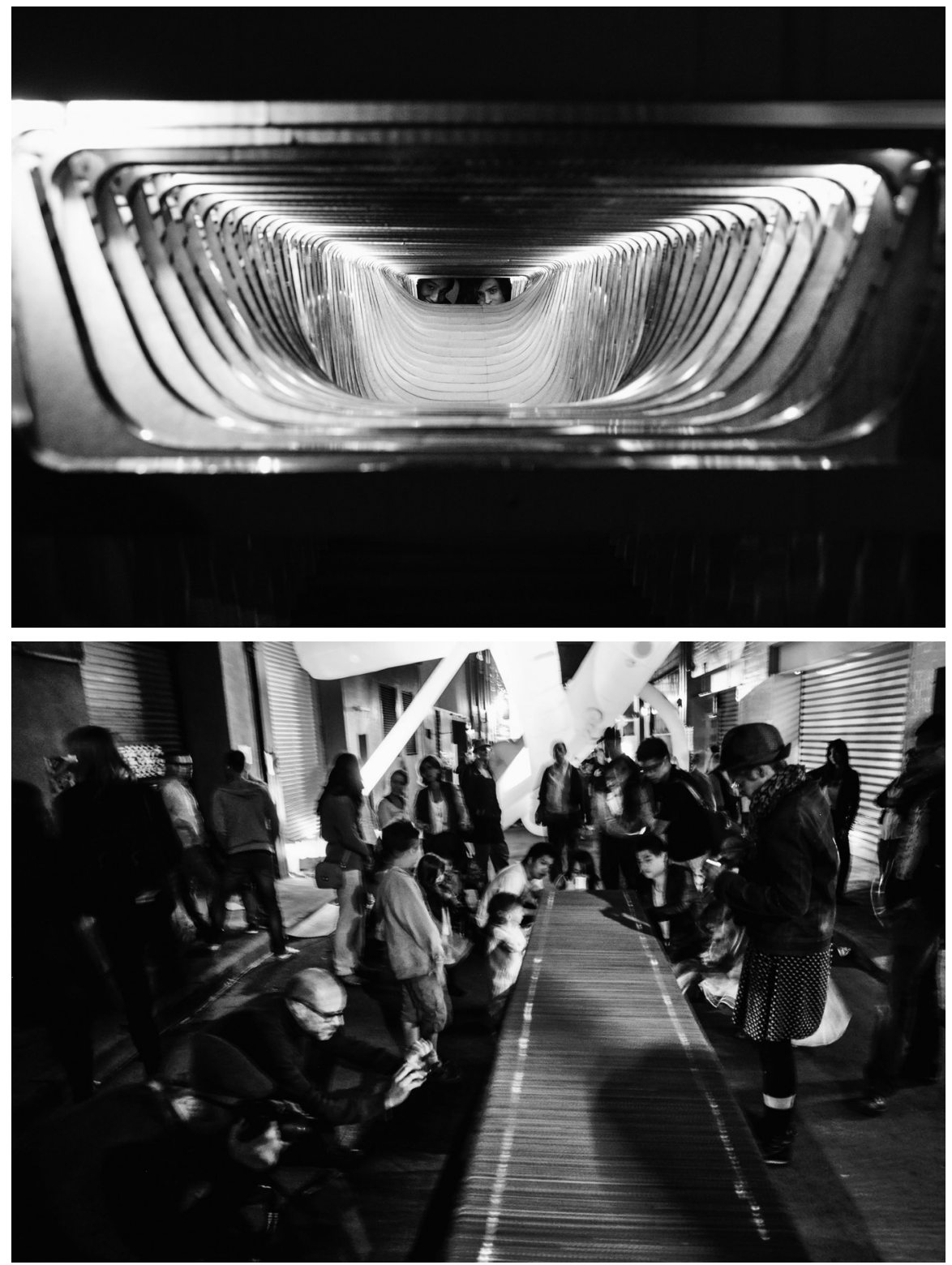

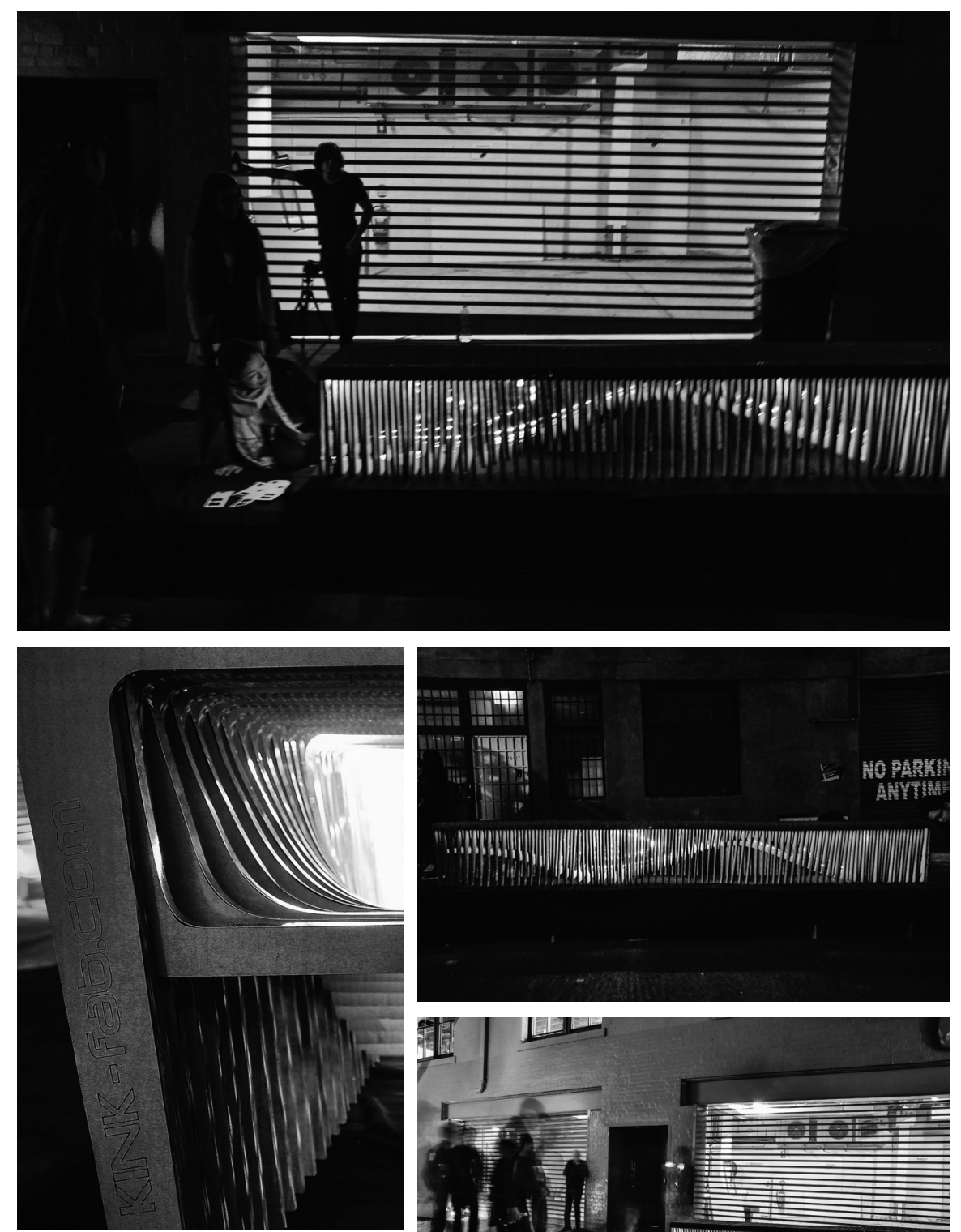

Figures on this spread: SOCIOLANTERN

- an infrastructural object that combines lighting and seating by UTS architecture students James Lauman, Jordan Soriot, and lighting design student Ilana Thorpe. [Photos: James Lauman and Jordan Soriot, 2012]
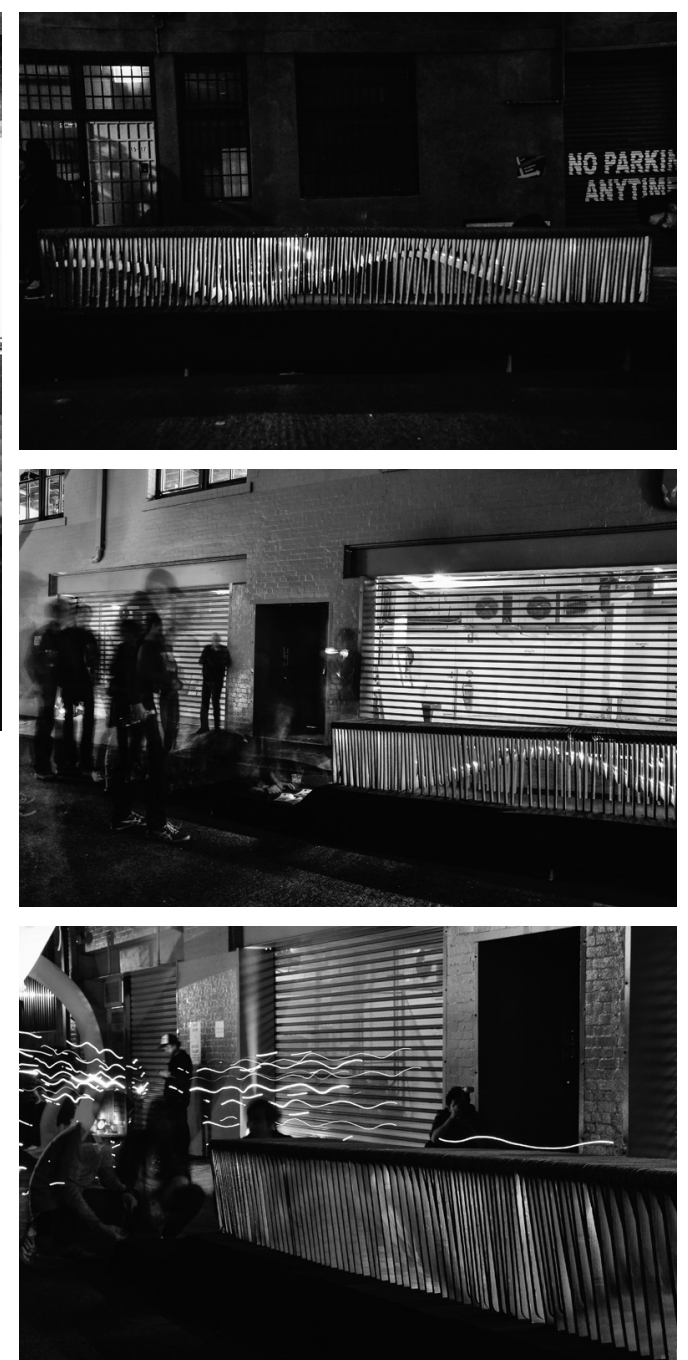
While the SOCIOLANTERN project promised a sense of utilitarian extravagance, other installations were less useful but no-less spectacular and engaging. JELLY FISH, a project by students Hyuna Lee, Jane Lee and Mattia Bravin, transported visitors into a sphere of floating luminosity with a hanging sculpture fabricated of translucent, warped plastic sheets. Hovering a metre off the ground, the trapezoidal structure provided a discrete opening, inviting visitors to slip inside to enjoy a dive into an immersive world of radiant colour surges. At the heart of the project were the material and tectonic qualities of translucent plastic sheets. Cut, warped and interconnected, the sheets materialised as a light-weight structure which assumed a unique form determined by the geometry of the cutting patterns and self-weight of the material.

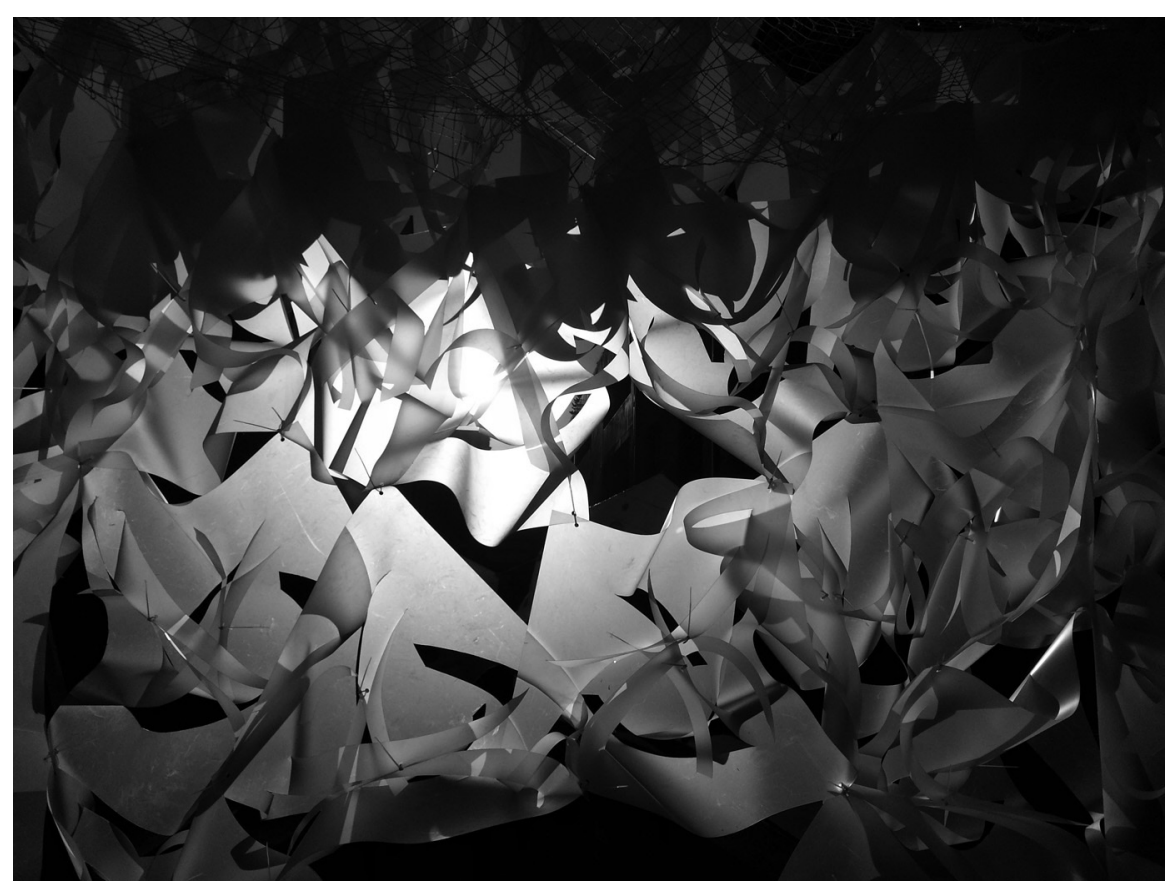



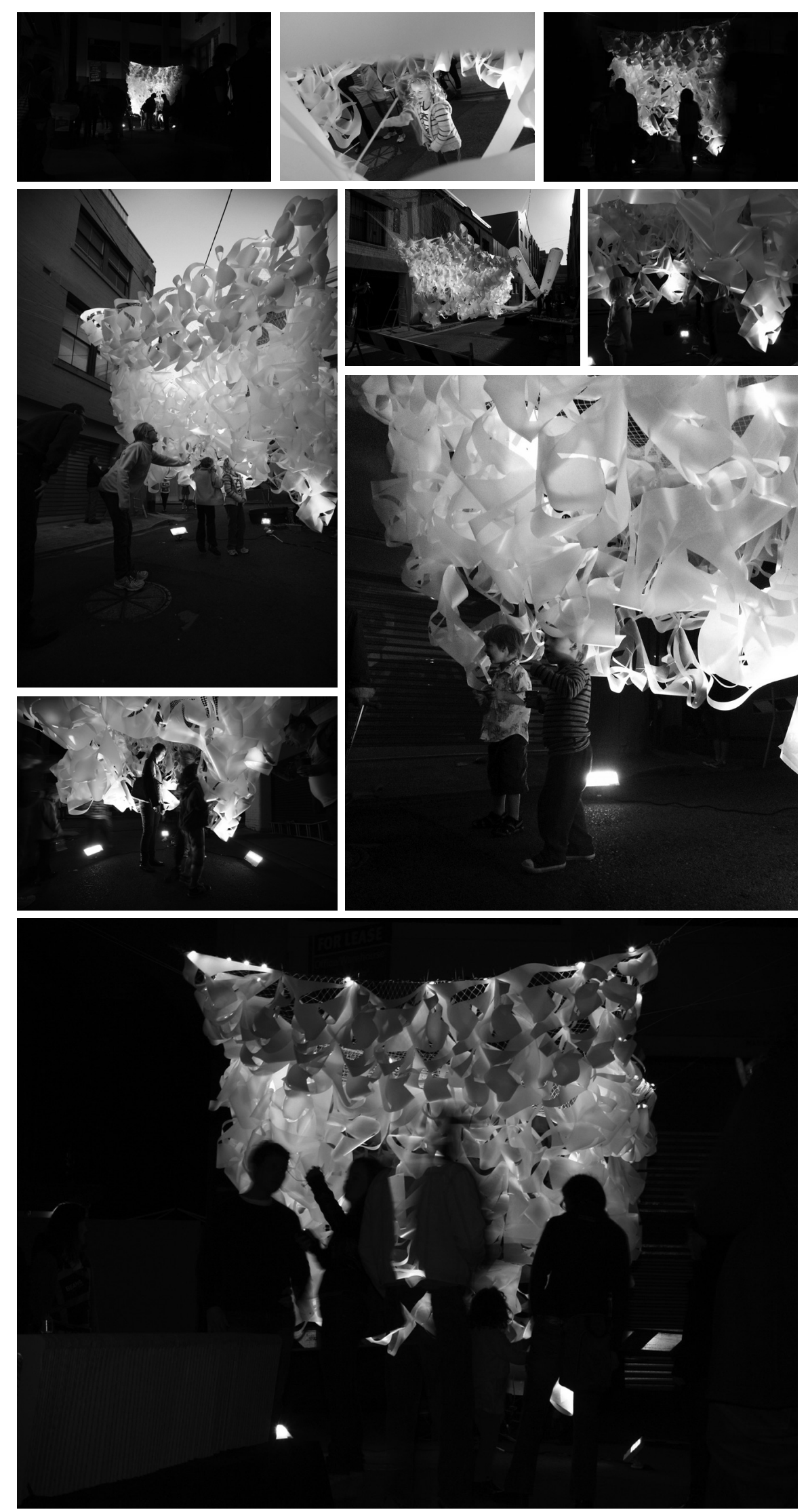

Figures on this spread: JELLY FISH a luminous installation that provided immersive experiences for visitors, designed by UTS architecture students Hyuna Lee, Jane Lee and Mattia Bravin with lighting design student William York. [Photos: Hyuna Lee and Jane Lee, 2012] . 

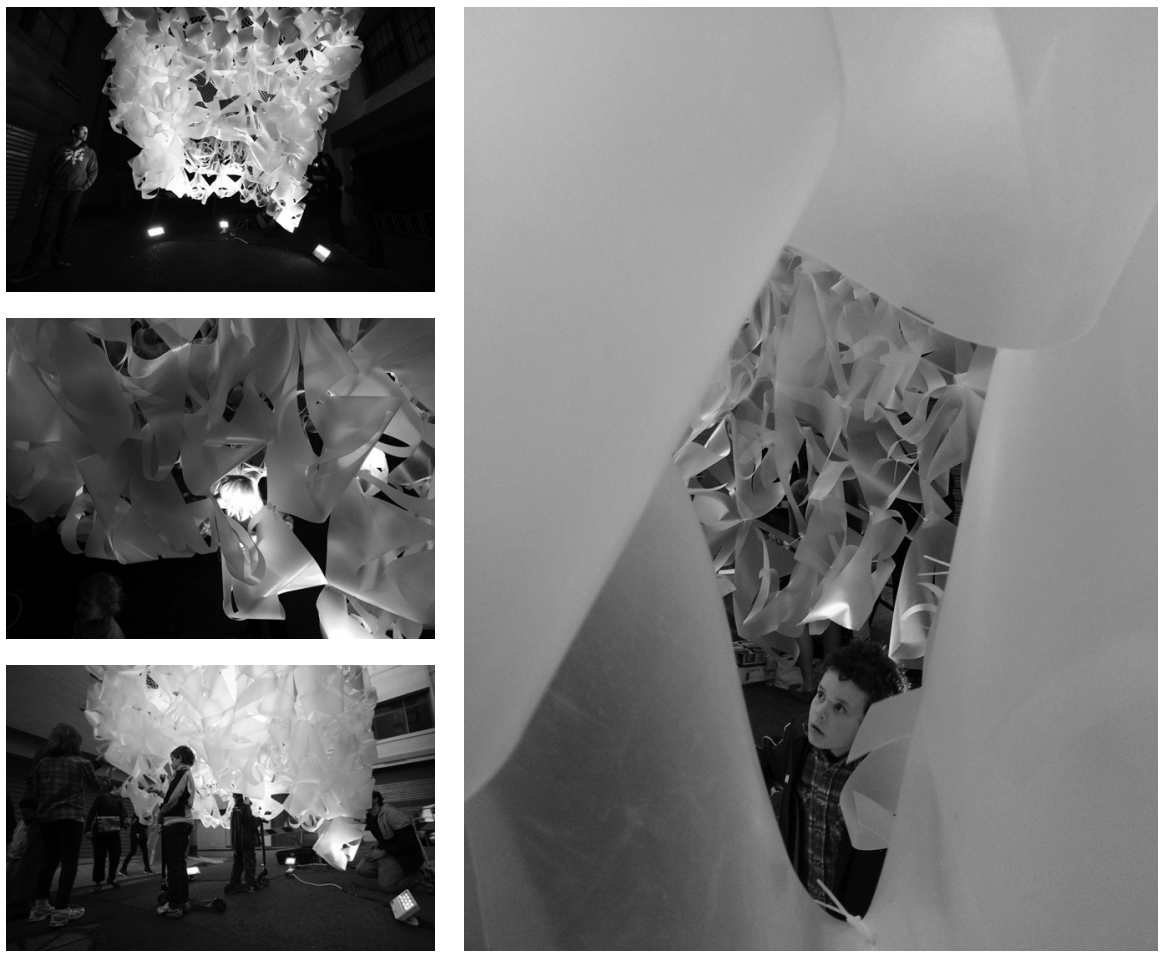

Figures on this page: JELLY FISH - a luminous installation that provided immersive experiences for visitors, designed by UTS architecture students

Hyuna Lee, Jane Lee and Mattia Bravin with lighting design student William York. [Photos: Hyuna Lee and Jane Lee, 2012]

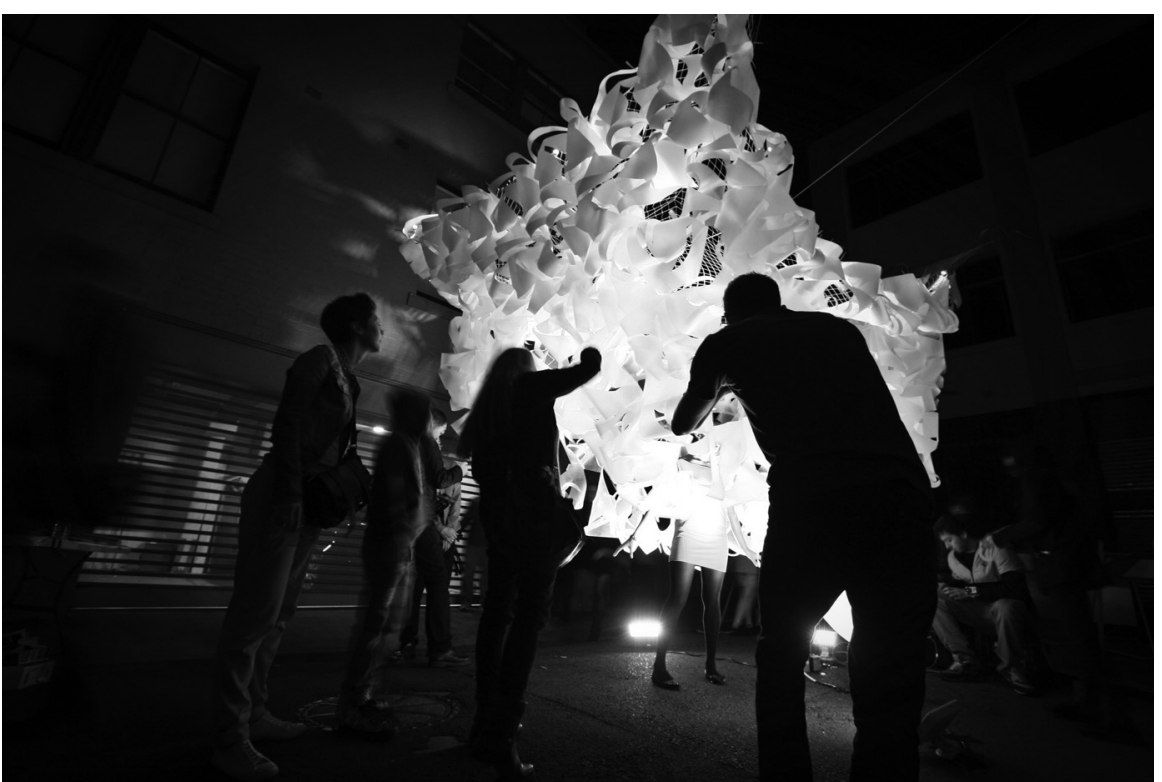




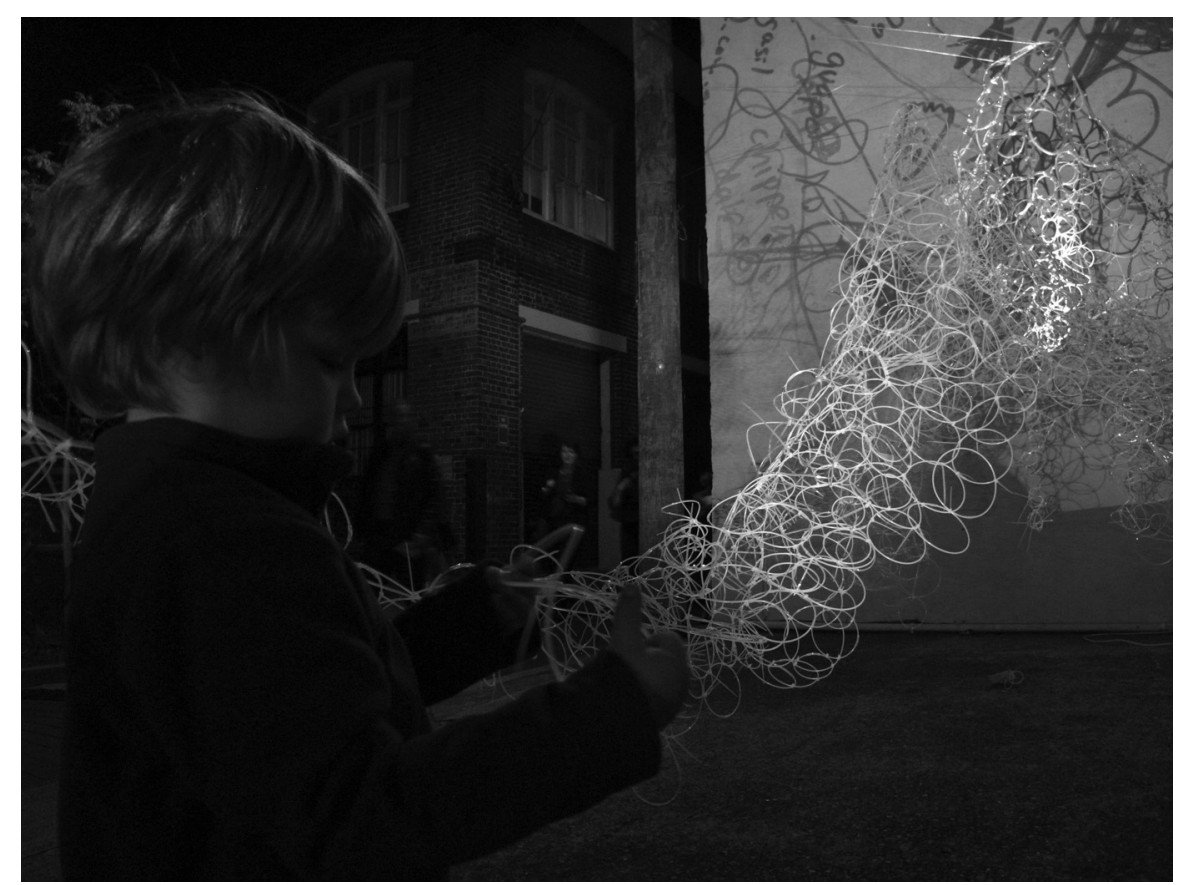

Figures on this page: NYLON BEAM an installation that invited visitors to interact with the light and shadow effects of the installation by drawing. Designed by UTS architecture students Mona Parvaresh and Luxsina Thunyaprateep with lighting design student Namrata Madan. [Photos: Mona Parvaresh and Luxsina

Thunyaprateep, 2012]
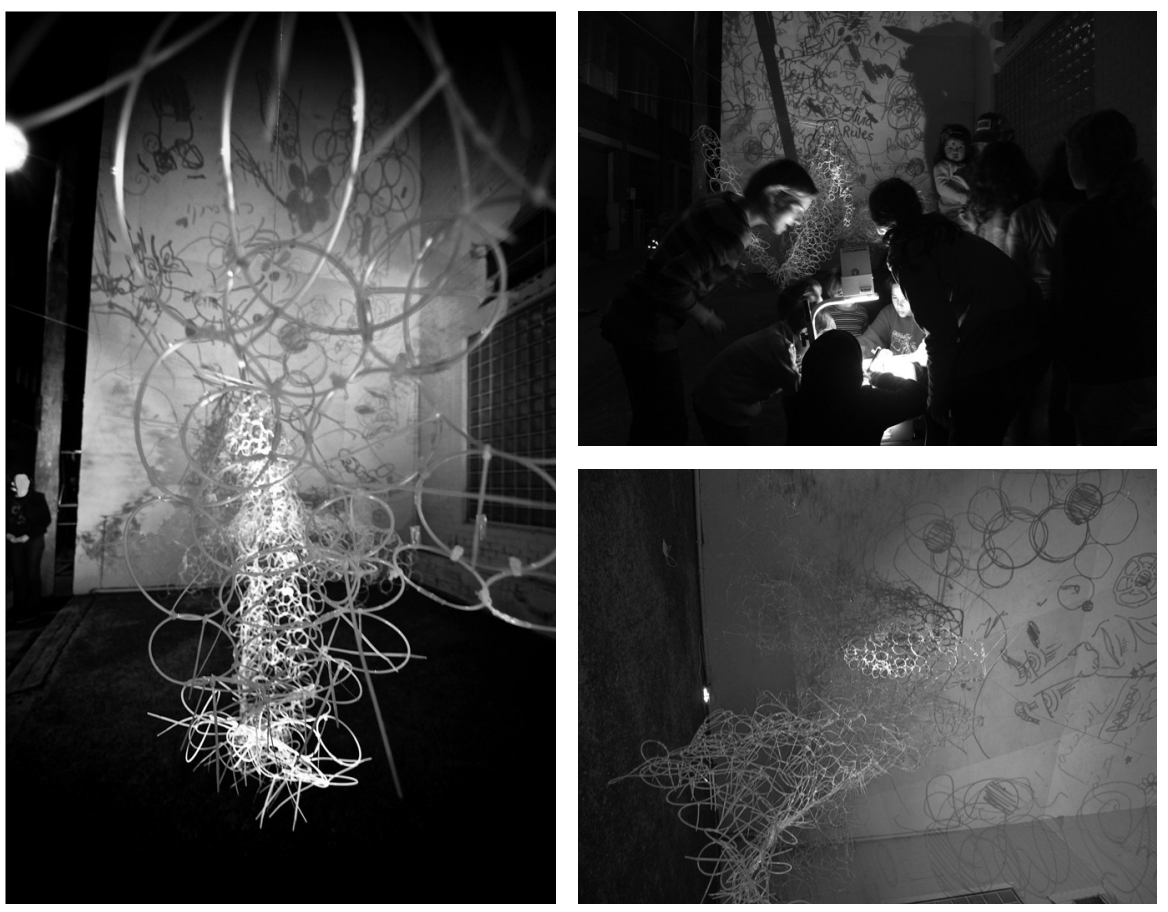
10

7

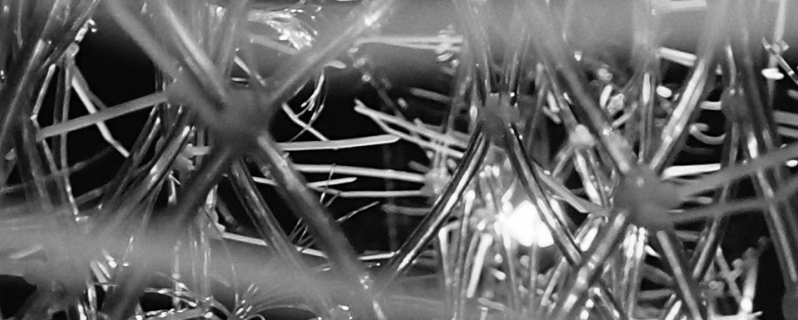

A 32

Wint -

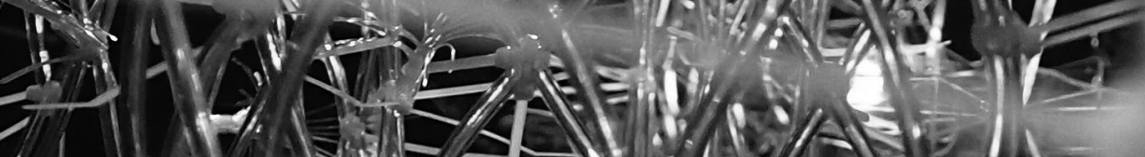

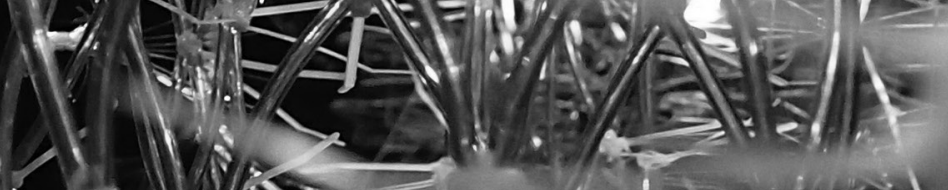

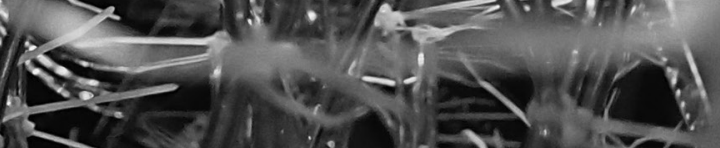

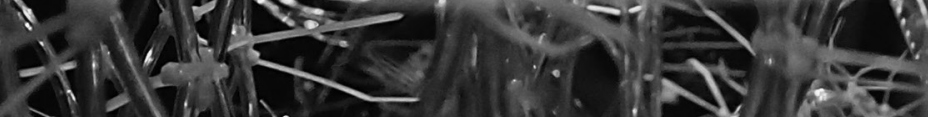

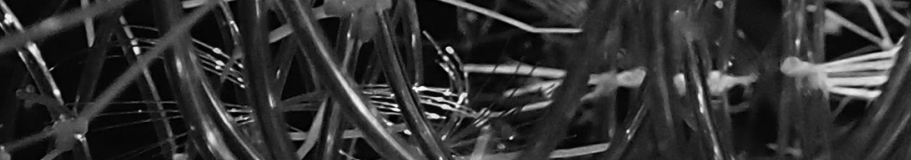

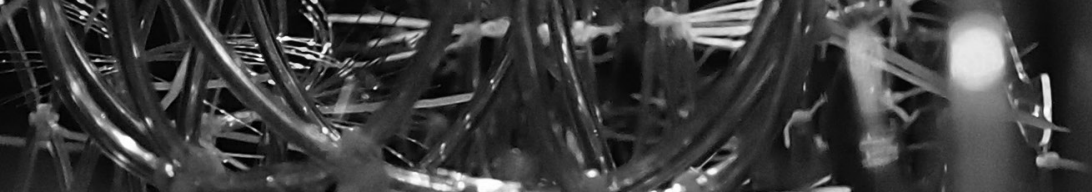

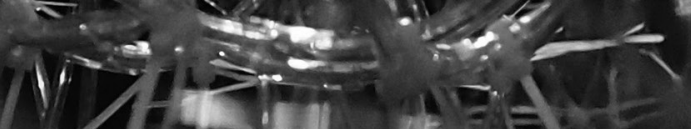

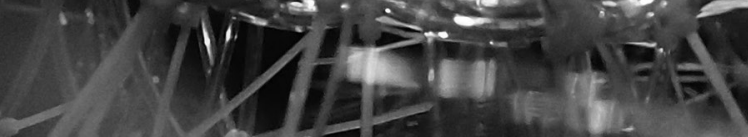

3. $19=5=1$

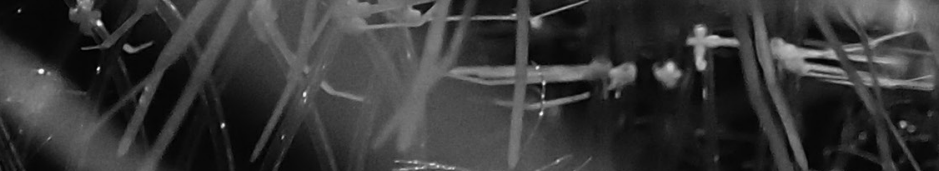

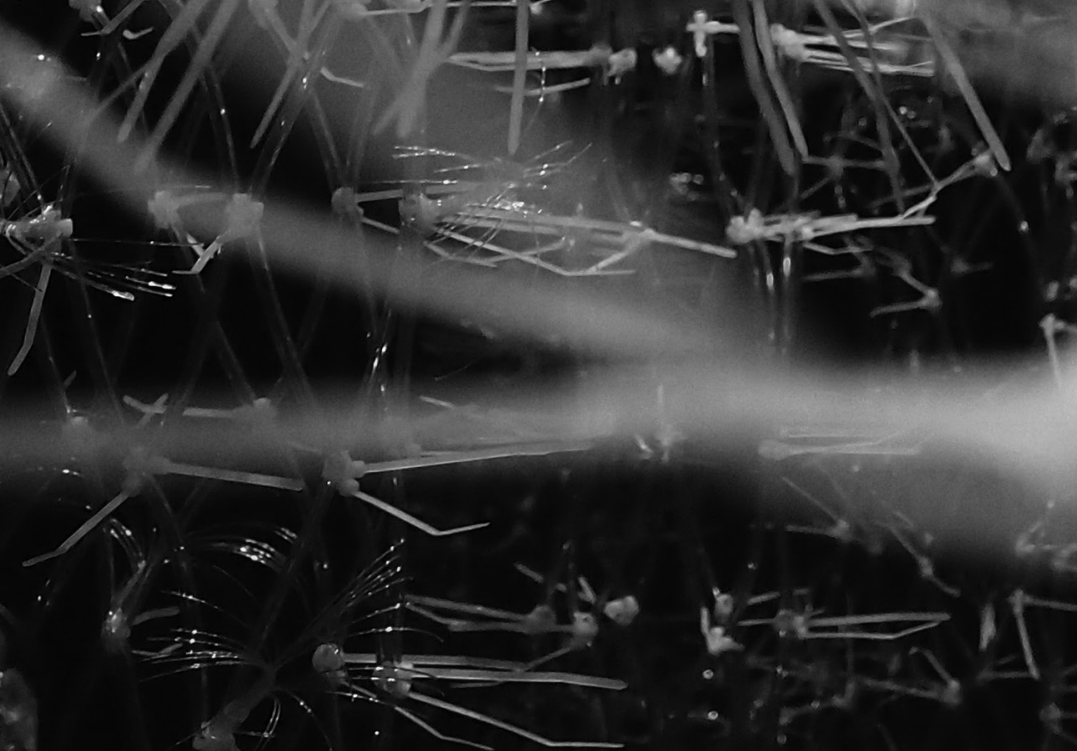


At the UTS Architecture School, interdisciplinary collaboration and public engagement through built projects are becoming important parts of the postgraduate curriculum. Events such as BEAMS offer opportunities for testing students' design rigour and collaborative skills in the face of real life situations where the pressures of resourcing, fabrication, erection, budgets and time lines are experienced firsthand. Direct contact with end users provides a valuable testing ground for ideas and assumptions that are rarely interrogated in a university environment. With this type of studio, the UTS Architecture School attempts to support students in developing initiative and independence, confidence in decision making and negotiation processes, and leadership and team skills. The UTS student participation in BEAMS 2012 indicates that this direction is proving successful.

The project was instigated and co-ordinated by Sandra Karina Löschke of the UTS Architecture School and Michael Day of the UTS School of Design.
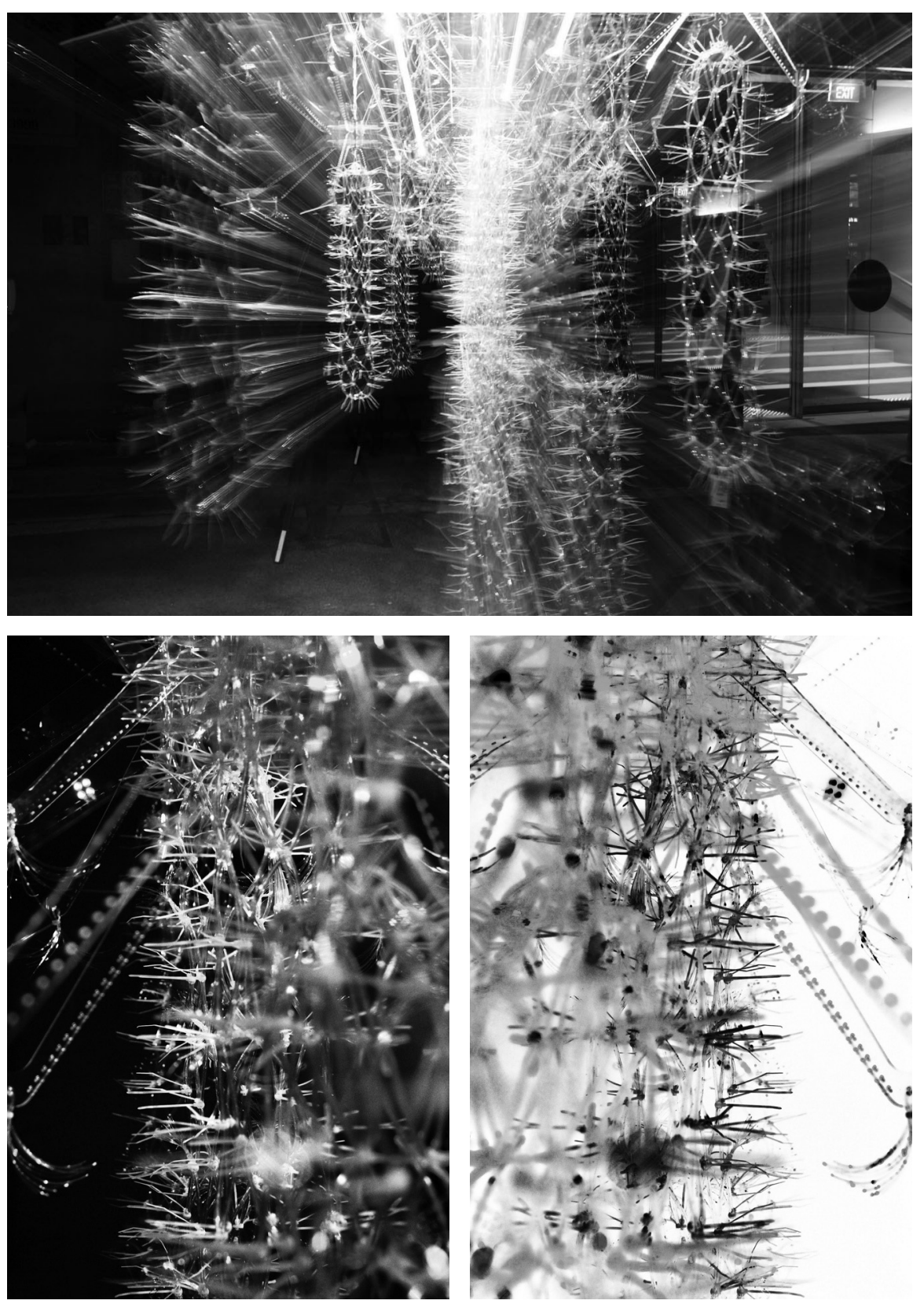

Figures on this spread: NERVES designed by UTS architecture students Ying Su and Chen Zhuang with lighting design student Parnmoonin Komkham. [Photos: Ying Su and Chen Zhuang] 